\title{
Technique
}

\section{Altertative trophy measuring techniques for African buffalo}

\author{
S.E. Gandy and B.K. Reilly
}

Gandy, S.E. and B.K. Reilly. 2004. Altertative trophy measuring techniques for African buffalo. Koedoe 47(1): 119-124. Pretoria. ISSN 0075-6458.

\begin{abstract}
The African buffalo is considered the classic African trophy. It is the choice of many hunters who will never go on to hunt any of the other dangerous game animals on the continent. A good trophy is perceived as that of a mature bull with a hardened boss and horn tips that lengthen into sharply pointed hooks. However, indications are that these are the bulls in their breeding prime and there is concern that the continued targeting of these individuals will negatively impact on the population dynamics of the herds, ultimately affecting the sustainability of buffalo hunting. As they age and become postreproductive, the horns broom down, reducing the trophy score under the current measurement systems. A new measuring system is needed that encourages hunters to target the older post-reproductive bulls, instead of those that are still breeding. A random sample of trophies was divided into broomed and non-broomed sub-samples. All key parameters that can be measured in the trophy were measured with a view to identifying the parameters that would allow broomed-down individuals to compete favourably with the non-broomed "classic trophy" in the primary measurement systems, those of Safari Club International and Rowland Ward. An index, created through dividing tip space by the mean of the two individual horn lengths proved to serve the purpose. This factor was then applied to the mean of the SCI and Rowland Ward measurements in the samples. These methods allowed broomed horns to score more points in the record books than non-broomed horns. Boss width and boss space are other possible measurement inclusions that could be considered.
\end{abstract}

\section{S.E. Gandy and B.K. Reilly $\triangle$, Department of Nature Conservation, Tshwane Univer-} sity of Technology, Private Bag X680, Pretoria, 0001 Republic of South Africa.

\section{Introduction}

The African buffalo has always attracted attention, not only because of its value as a member of the 'big five', but also because of its spectacular qualities from the sportsman's point of view. Most hunters regard them as one of the ultimate trophies. By nature, buffalo are unpredictable and therefore difficult and dangerous to get close to, so the true spirit of hunting - fear, fascination, and a test of the hunter's skills - is the main reason why every dedicated hunter desires to devote a period of his or her hunting career in pursuit of the finest trophy (Grobler 1996).

Trophy hunting is a specialised form of game utilisation, where adult males are selected for their trophy value. Buffalo bulls reach sexual maturity at 4-5 years (Estes 1997), but the trophy is still 'green' at this stage and not of much value as a trophy. The trophy reaches its full potential when the boss hardens to form the so-called armour plates, and the horns are fully grown out to form the characteristic hooks. At this stage the points are still sharp and well formed. Authors estimate age at 7 to 12 years in contrast to Sinclair's (1977) visual estimate of 5 to 10 years of age.

As they become older, their boss closes up completely and the horn tips wear down more and more to form the typical 'old bull' shape (Grobler 1996). 


\section{SCI Measuring Method}
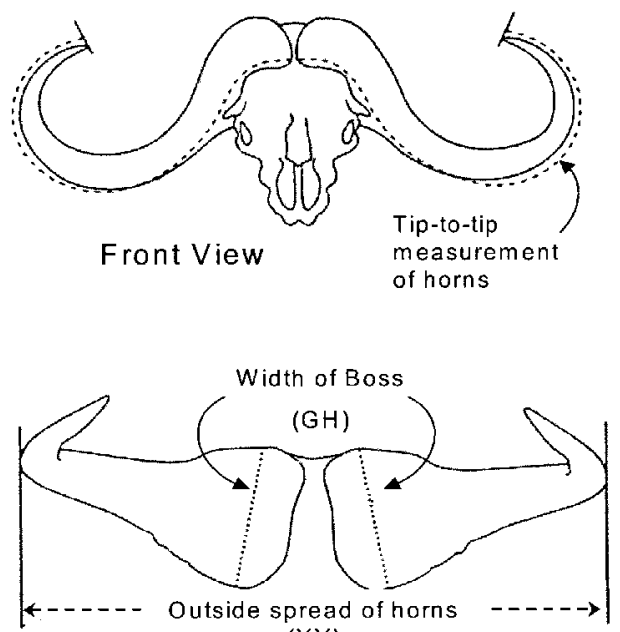

$(X Y)$

\section{Rowland Ward Measuring Method}

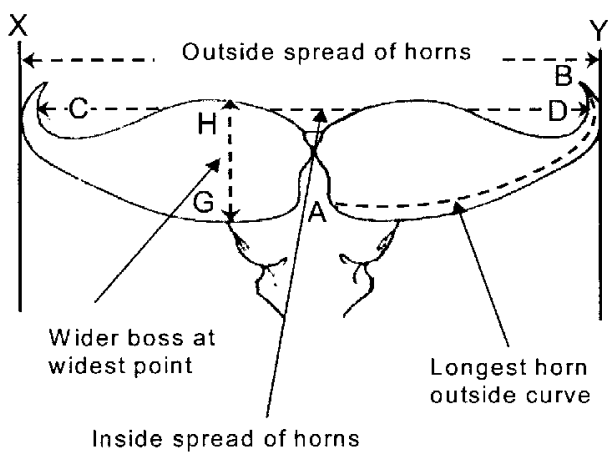

Tip-to-tip measurement of horns also included

Top View

Fig. 1. Diagrammatical representation of the current measuring methods as applied by Safari Club International and Rowland Ward.

The dominant trophy measuring systemsSafari Club International (SCI) — encourages hunters to target soft-bossed, "green" bulls and horn tips sharply pointed and well formed, as this is when a trophy scores the highest points in the record books. These bulls are in their prime, however, and at peak breeding status within the herds.

It is believed by a number of researchers, veterinarians and the African safari industry (e.g., Grellmann, anvo@mweb.com.na pers. comm.; Heath, fishunt@samara.co.zw pers. comm.; Robertson 1996) that to hunt them at this age cuts short their genetic contribution, whereas the older bulls have already passed on their genes and left the herds to live solitary existences. These individuals and organisations all suggest that by giving a bias to the boss in SCI's measuring system will solve the problem, encouraging trophy hunters to harvest older males.

Grellmann (pers. comm.) also encourages modifying SCI trophy scores for antelope so that those with larger base circumferences ranked the highest, believing this would help select older post-reproductive males with broomed-down horns.

SCI requires 100 points (Fig. 2), reached by adding the two boss width measurements to the total length of the horns from one tip to the other over the forehead (Quimby 1993). Under the SCI measuring system, once the horns broom down to 'old bull' status, the trophy scores less points in the record books because of the decline of total width and total length. A new measuring system is needed that allows older, worn-down trophies to compete with bulls in their prime. This will allow enough time for bulls to complete their breeding while simultaneously allowing for a better reflection of the trophy as a function of the age of the animal, which will ultimately contribute to the economic and possibly ecological sustainability of buffalo hunting.

Rowland Ward's scoring, using the outside spread, is also believed inadequate since different populations of buffalo may have genetically and/or environmentally (e.g., food availability, nutritional constituency of food supply or physical environment) pre- 
determined tendencies for larger or smaller outside spreads. For instance Tarangire and Moyowosi buffalo populations in Tanzania, on the average, have the reputation for significantly larger outside spreads than Okavango and Zambezi Delta buffalo. A 44-inch buffalo in the Moyowosi, Tanzania can be soft bossed "green," scoring well in Rowland Ward, while a 34-37 inch outside spread buffalo in the Zambezi Delta may be mature with hard closed bosses. Therefore, scoring by the outside spread alone does not guarantee that one shoots an older hard bossed tending towards post-reproductive buffalo.

The minimum score for a Rowland Ward buffalo trophy is 47 inches, taken from the widest outside spread (Halse 1998) (Fig. 1). Today, very few buffalo make it into Rowland Ward. Not only are SCI's record book minimums easily attainable, but also today the majority of hunters follow this scoring system.

\section{Current measuring system}

\section{Safari Club International (Fig. 1)}

Tip-to-tip measurement of horns

The combined lengths of both horns are measured, from tip to tip across the forehead. Using a measuring cable, measurement is begun at one horn tip and follows the hairlike grain of the horn, around its outer curve to its lowest point. The cable is pivoted and the shortest distance along the underside of the horn to the forward edge of the boss measured, keeping the cable in constant contact with the horn. This line will cross the grain of the horn, not run parallel to it. From the forward edge of the boss, the forehead is bridged directly across to the same point on the other boss edge. The cable is kept taut, not pressed into the boss gap. The process is repeated to the opposite horn tip (Fig. 1).

\section{Width of boss}

The surface width of each horn boss is measured at its widest point. This measurement should be at an approximate right angle to
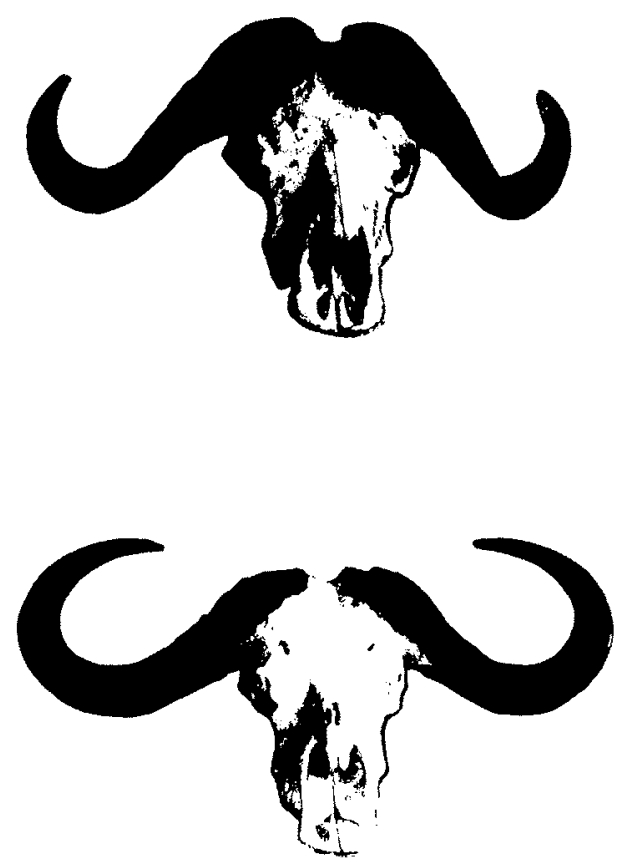

Fig. 2. Examples of broomed (top) and non-broomed (bottom) buffalo horns.

the longitudinal axis of the horn. Once the widest point has been determined, the measurement will include the top surface of the boss, the surfaces of the rear edge plus the surface of any front edge that exists. Only hard black horn is measured. So-called 'green' horn (which will boil away) or skull bone are not included (Fig. 2).

All measurements are totaled to produce a score that can be submitted for record book purposes.

\section{Rowland Ward (Fig. 1)}

1. The greatest outside spread in a straight line is measured, at right angles to the axis of the skull (X-Y).

2. The greatest inside spread at the widest point between the curves of the horns (C-D).

3. Measuring the length of the longest horn on the outside curve begins at the front lower corner of the boss along the front 
Table 1

Mean horn parameters (inches) for 14 'broomed' and 15 'non broomed' randomly selected buffalo trophies

\begin{tabular}{lcccccccccc}
\hline & $\begin{array}{c}\text { Left } \\
\text { boss }\end{array}$ & $\begin{array}{c}\text { Right } \\
\text { boss }\end{array}$ & $\begin{array}{c}\text { Outside } \\
\text { spread }\end{array}$ & $\begin{array}{c}\text { Tip-to-Tip } \\
-\end{array}$ & $\begin{array}{c}\text { Left horn } \\
\text { Length (B) }\end{array}$ & $\begin{array}{c}\text { Right horn } \\
\text { Length (C) }\end{array}$ & $\begin{array}{c}\text { Tip } \\
\text { Space (A) }\end{array}$ & $\begin{array}{c}\text { Boss } \\
\text { space }\end{array}$ & SCI & RW \\
\hline $\begin{array}{l}\text { Non-roomed } \\
\text { Broomed }\end{array}$ & 12.78 & 13 & 37.8 & 75.5 & 35.32 & 35.23 & 26.13 & 4.89 & 101.3 & 37.17 \\
\hline
\end{tabular}

SCI - Safari Club International RW - Rowland Ward

Table 2

Various horn parameters (inches) and resulting SCI and Rowland Ward scores after application of an index (dividing the tip space measurements by the mean of the two individual horn lengths squared), the quantity squared - designed to advantage broomed-down animals

\begin{tabular}{lccccccc}
\hline & $\begin{array}{c}\text { Factor } \\
[\mathrm{A} /(\mathrm{B}+\mathrm{C}) / 2] 2]\end{array}$ & $\begin{array}{c}\text { Outside } \\
\text { spread }\end{array}$ & Tip-To-Tip & $\begin{array}{c}\text { Left horn } \\
\text { Length }\end{array}$ & $\begin{array}{c}\text { Right horn } \\
\text { Length }\end{array}$ & SCI & RW \\
\hline Non-broomed & 0.55 & 20.70 & 41.53 & 19.43 & 19.37 & 55.72 & 20.79 \\
Broomed & 0.93 & 33.48 & 60.45 & 28.22 & 29.02 & 86.03 & 33.48 \\
\hline
\end{tabular}

SCI - Safari Club International

RW - Rowland Ward

Table 3

Summarized means (inches) of sampled buffalo trophy measurements of SCI, Rowland Ward and proposed alternative methods

\begin{tabular}{lcccccc}
\hline & SCI & RW & $\begin{array}{c}\text { SCI New } \\
\text { Method }\end{array}$ & $\begin{array}{c}\text { SCI New } \\
\text { Method/ } \\
\text { Boss Space }\end{array}$ & $\begin{array}{r}\text { RW New } \\
\text { Method }\end{array}$ & $\begin{array}{c}\text { RW New } \\
\text { Method/ } \\
\text { Boss Space }\end{array}$ \\
\hline Non-broomed & 101.3 & 37.8 & 55.72 & 11.39 & 20.79 & 4.25 \\
Broomed & 92.5 & 36 & 86.03 & 24.58 & 33.48 & 9.57 \\
\hline
\end{tabular}

SCI - Safari Club International

RW - Rowland Ward

edge, inclining to the outside surface of the horn and continues to the tip (A-B).

4. The spread or tip-to-tip distance is measured (C-D).

5. The width of the wider boss, at its widest point, beginning where the horn meets the skull in the front over the top of the boss and ending where the horn meets the skull at the back. The line of measurement is to be parallel to the axis of the skull (G-H) (Fig. 1).

For scoring purposes, only the outside spread is recorded.

\section{Method}

A random sample of 29 trophies from taxidermists around Pretoria were selected and subjectively divided into two sub-samples, 14 broomed down (old bull) trophies and 15 non-broomed (prime bull) trophies (Fig. 2). Taylor (1988) has provided ageing techniques based on tooth morphology but no attempt was made to accurately age the trophies in the sample.

The following parameters were measured for each set of horns:

- Outside spread

- Boss width of both horns at widest point

- Tip-to-tip (combined lengths of both horns 
across forehead)

- Individual horn lengths of both horns

- Tip space (distance between the two horn tips)

- Boss space (space between the two bosses) (Fig. 1).

Data was recorded in inches, to the nearest $1 / 8$. These parameters were considered to be all the parameters that contribute to both the two and threedimensional descriptors of the size of the "trophy".

The SCI and Rowland Ward scores for each trophy were totaled in both samples.

The mean was calculated for each measurement and the two samples compared. The additional parameters measured were used to explore indices that would change the profile of "trophies" in favour of older broomed-down individuals.

\section{Results}

The importance of this exercise is to demonstrate that trophy measurement parameters can be employed to score sport-hunted trophies that encourage hunters to select for older post-reproductive animals.

Table 1 shows that the boss width and the tip space are the only two measurements where broomed-horn trophies scored higher than non-broomed. Working with the tip space measurement, it was decided to create a factor with this measurement and the mean of the two individual horn lengths. Nonbroomed bulls tend to have individual horn lengths longer than the tip space while broomed bulls have horn lengths close to or even shorter than the tip space (Figs. $1 \& 2$ ).

Dividing the tip space measurements by the mean of the two individual horn lengths and then squaring the result derived this factor. The non-broomed measurements became fractions with a mean of 0.55 while the broomed measurements showed a mean of 0.93 . The higher the value of the factor, therefore, the longer the tip space measurement in relation to the mean of the individual horn lengths. Some of the broomed samples even exceeded 1, showing that the tip space measurement was longer than the mean of the individual horn lengths. Where nonbroomed horns scored higher than broomed horns under existing measurement systems, all measurements were multiplied by the factor calculated for each trophy. The means for these calculations of the non-broomed horns were significantly lower than the means of the broomed horns (Table 2).

As prime bulls age, the boss thickens and begins closing up, thus reducing the distance (boss space) between the two horns.

To magnify the broomed trophy score even more, the total trophy score can be divided by the boss space measurement (Table 3).

One shortcoming in the above analysis is that it requires separating out broomed and non-broomed trophies and computing a separate multiplication factor for each category, something that SCI and RW may be unwilling and/or are incapable of doing with the data on hand if the goal is to go back and rectify older records in order to come up with a new set of listings based on recognition of age. It is also unlikely that they will be willing to require the separation of "broomed" versus non-broomed animals, as this can be subjective, and might give quite varying results with a wide standard error if many individuals as opposed to one researcher were making this decision.

Neither SCI nor Rowland Ward currently recordst boss-space measurements, and only Rowland Ward collects tip-space measurements as supplemental data. However, both scoring systems measure boss width.

Future research might focus on analysing the use of standard boss-width measurements combined with "a single multiplication factor", as opposed to two that can be applied to buffalo trophy measurements across-theboard to encourage a similar selective bias for old age in hunted buffalo. This will be required to enable both SCI and Rowland Ward to easily adjust existing data in their trophy record books. Similar analyses (i.e., base circumference) are needed for antelope species.

Of course the other option is to leave the old records stand, while all new records would apply the new measurement scoring method, as happened with the development of a new javelin in track and field back in the 1980s. 
This would also require SCI to begin collecting additional data.

Regardless of the direction taken, future research must be undertaken in close collaboration and negotiation with the record book associations and their sport hunting members to assure that the results from the research will be applied in a manner that improves the management of the buffalo and/or other species for which research had been undertaken.

However, the most difficult challenge confronting the scientific community will not be coming up with these conversion figures, but changing the mind-set of the sport hunters who currently dominate the market, that "bigger is not necessarily better" while providing the scientific data to demonstrate that by modifying their current systems of measurement they are enhancing the economic and possibly the ecological sustainability of the species.

\section{Conclusions}

From the above calculations it can be concluded that trophies with factors close to or above 1 , are generally much older bulls with worn horn tips. They should be scoring more points in the record books than trophies with low factors. In other words, the closer (or even exceeding it) to 1 the factor is, the better the trophy.

The proposed new trophy measuring method computes a multiplication factor created by dividing the tip space measurements the mean of the two individual horn lengths and then squaring the result.

With this method, a good trophy should have the following attributes:

- a wide tip space in relation to individual horn lengths

- a wide outside spread

- large boss widths

- a small boss space

There are undoubtedly some factors that may influence new scoring methods-current research in the Kruger National Park is showing that older bulls act as buffers for predators (Bowers, P.O.Box 76, Skukuza, 1350, RSA pers. comm.). The issue of boss space also needs further investigation, as this appears to open again in very old animals (Bowers pers. comm.).

In this limited experiment we have seen that a minor change to the trophy measuring system can shift the emphasis on different sectors of a population being utilised and lead to a more conservation-minded approach to trophy hunting of buffalo.

Future research needs to focus on computing a "single" multiplication factor based upon boss-width measurements, which both record scoring systems collect, while providing scientific evidence that by modifying their scoring systems, the international sport hunter is helping to assure quality wildlife trophies for the next generation of hunters and, as importantly, sustain the role hunting plays to rural and national economies in Africa.

\section{References}

BothMA, J. DU P. 1996. Game ranch management. Pretoria: Van Schaik.

Estes, R.D 1997. The behavior guide to African mammals. Halfway House, South Africa: Russel Friedman.

GroBlER, D.G 1996. The potential utilization of the African buffalo with regard to hunting and meat production. In: PENZHORN, B.L. (ed.). Proceedings of a symposium on the African buffalo as a game ranch animal. Pretoria: Onderstepoort.

HALSE, A.R.D (ed.). 1998. Rowland Ward's records of big game. Hartam, South Africa: Rowland Ward.

QUIMBY, W.R (ed.). 1993. SCI record book of trophy animals, African field edition, Vol. 1. Tucson, Arizona: Walsworth.

RoberTson, K. 1996. Nyati. A guide to hunting Zimbabwe's most dangerous big game. The Southern Buffalo. By 'Doctari'. The Zimbabwe Hunter Magazine (now African Hunter). Harare, Zimbabwe: Magset.

TAYLOR, R.D. 1988. Age determination of the African buffalo, Syncerus caffer (Sparrman) in Zimbabwe. African Journal of Ecology 26(3): 207-220.

Sinclair, A.R.E. 1977. The African buffalo. Chicago: University of Chicago Press. 